\title{
Comunicação
}

\section{Os espaços cervicais profundos e seu interesse nas infecções da região}

\author{
M.D. Durazzo, F.R. Pinto, M.S. da Rocha Loures, E.M. Volpi, S. Nishio, L.G. Brandão, A.C. Cordeiro, \\ A.R. FERRAZ
}

Disciplina de Cirurgia de Cabeça e Pescoço do Hospital das Clínicas da Faculdade de Medicina da Universidade de São Paulo, São Paulo, SP.

\begin{abstract}
RESUMO - As infecções dos espaços cervicais profundos, embora raras, associam-se a alta morbimortalidade. A abordagem cirúrgica faz-se necessária na maioria dos casos e se baseia no conhecimento da complexa anatomia das fáscias cervicais e dos espaços cervicais profundos.

Овј EтIvo. Apresentar considerações anatômicas de interesse prático sobre fáscias e espaços do pescoço, sua conceituação e nomenclatura, relatando, a título de exemplo, quatro casos de infecções dos espaços cervicais profundos.

Material e Método. São apresentados um caso de angina de Ludwig complicada com mediastinite, pericardite, pneumonia, empiema pleural, fístula esofágica e choque séptico, um caso de abscesso cervical espontâneo em paciente diabético, um caso de abscesso de loja submandibular e um caso de abscesso parafaríngeo iniciado após manipulação dentária. Nos quatro casos, a documentação ima-
\end{abstract}

\section{INTRODUÇÃO}

As infecções dos espaços cervicais profundos (IE CP) ti veram a inci dência acentuadamente diminuída com o advento dos antibióticos; atualmente, é muito raro encontrá-las em cirurgia geral. A pesar disso, constituem quadros graves que, se não forem tratados pronta e adequadamente, podem determinar o óbito.

Numerosas são as causas das IECP. Entre as mais freqüentes estão os focos sépti cos dentários (a origem mais comum em adultos) e as infecções faríngeas e amigdalianas (predominantes em crianças). Menos comuns são as injeções de drogas nas grandes veias do pescoço, os traumatismos, as infecções das glândulas salivares e a introdução traumática de corpos estranhos no local.

O tratamento consiste na instituição de antibióticos tão cedo quanto possível e, muitas vezes, na abordagem cirúrgica. Para isto, cumpre ao cirurgião estar familiarizado com a anatomia das fáscias cervicais e dos espaços determinados por tais fáscias, denominados espaços cervicais profundos. A revisão prática dos respectivos conceitos e topografia, tornados objetivos com a apresentação de genológica é rica e, em dois deles, evidencia o comprometimento de mais de um espaço profundo do pescoço.

Conclusões. A literatura enfatiza morbidade e mortalidade elevadas, etiologia diversificada (infecções dentárias, uso de drogas endovenosas, infecções do trato aerodigestivo alto e outras), a necessidade de traqueostomia em cerca de $\mathbf{5 0} \%$ dos casos e o emprego da terapêutica combinada (antibioticoterapia e abordagem cirúrgica do pescoço). Os métodos imagenológicos, como a tomografia computadorizada, são imprescindíveis no estudo de infecções dos espaços profundos do pescoço, tanto para a avaliação do sítio e extensão da afecção, como para o planejamento terapêutico.

UNITERMOS: Infecções cervicais. Infecções dos espaços cervicais profundos. Abscessos cervicais. Anatomia das fáscias cervicais. Angina de Ludwig.

quatro casos clínicos, constitui o propósito do presente trabalho.

\section{Anatomia das fáscias cervicais}

As fáscias cervicais e suas subdi visões determinam a formação de espaços virtuais, conhecidos como espaços cervicais profundos, normalmente úteis para o deslizamento dos vários constituintes do pescoço durante seus movimentos. N esses espaços, por vezes, desenvolvem-se as IE CP.

As fáscias podem ser divididas em fáscia cervical superficial (FCS) e fáscia cervical profunda $(F C P)^{1-3}$. A FCS é constituída por tecido celular subcutâneo que se estende da região zi gomática até o tórax e as axilas e envolve, em sua espessura, os músculos da expressão facial e o platisma. Essa fáscia é separada da F CP por um espaço virtual que pode ser utilizado como plano de dissecção durante esvaziamentos cirúrgi cos cervi cais e onde há tecido areolar frouxo, linfonodos, nervos e vasos, destacando-se a veia jugular externa.

A FCP é comumente subdividida em três camadas: superficial, média e profunda (figs. 1 e 2). A camada superficial da FCP (CSFCP) circunda totalmente o conjunto dos el ementos constituintes do 


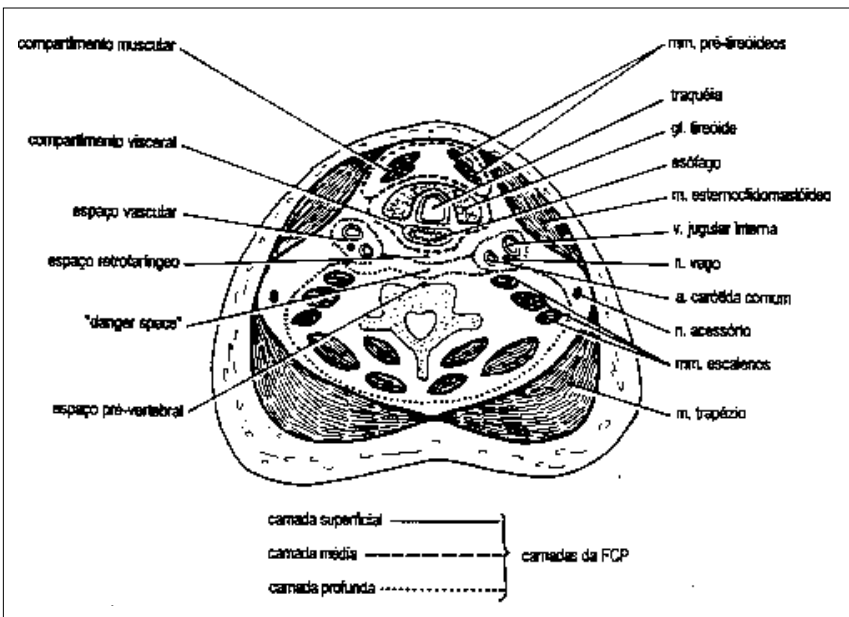

Fig. 1 - Esquema de corte axial do pescoço ao nível do istmo da tirói de mostrando a fáscia cervical profunda, suas camadas e os espaços por elas determinados.

pescoço e delamina-se para envolver, bilateralmente, os músculos esternoclidomastóideo, trapézio e as glândulas parótida e submandibular. A camada média da FCP (CMFCP) envol ve os músculos pré-tiróideos, esôfago, faringe, laringe, traquéia e glândula tiróide. É, por esse motivo, subdividida em duas porções: muscular e visceral. A camada profunda da FCP, do mesmo modo que a camada superficial, forma um envoltório completo da região, porém mais profundo, recobrindo músculos escal enos, el evador da escápula e esplênio da cabeça. É subdi vidida em duas camadas denominadas fáscia pré-vertebral e fáscia alar. É sobre a CPFCP que se encontram os elementos do feixe vásculo-nervoso do pescoço e o nervo frênico. Assim, por ocasião dos esvaziamentos cervicais, é o plano de reparo mais profundo da dissecção cirúrgica.

\section{Espaços profundos do pescoço}

Os espaços cervicais profundos (ECP) são, na verdade, espaços formados entre as fáscias cervicais ou suas divisões. A terminologia pode variar de um autor para outro - fato notadamente relacionado à complexidade da anatomia cervical ${ }^{1-3}$ porém, de forma prática, os ECP podem ser divididos em: 1) espaços supra-hióideos; 2) espaços infra-hióideos; e 3) espaços local izados ao longo de todo o pescoço.

1) Acima do osso hióide, bilateralmente, temos os seguintes ECP: a) espaço submandibular, subdividido em espaços submaxilar e sublingual, separados pelo músculo milo-hióide; b) espaço mastigador, onde encontramos o ramo ascendente da mandíbula, músculo masseter, musculatura pterigóidea e porção inferior do músculo temporal; c)

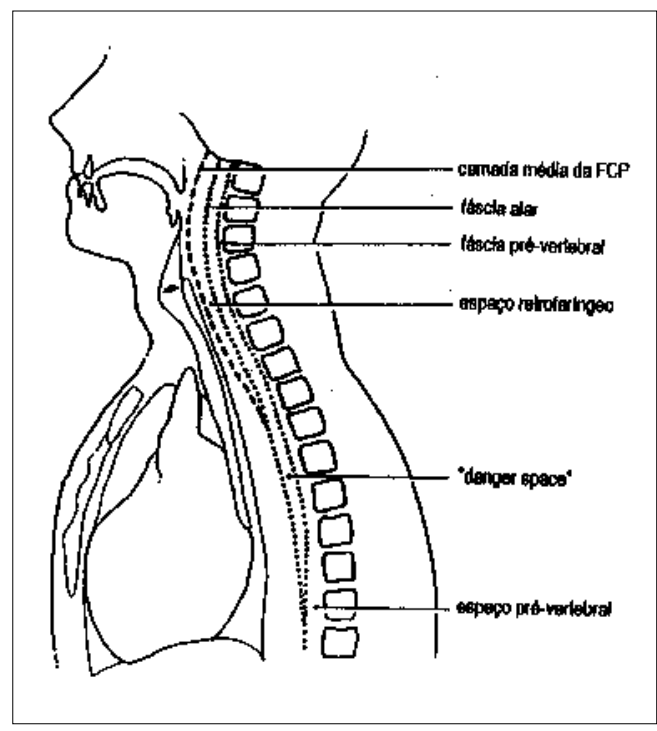

Fig. 2 E squema de corte sagital mediano do pescoço.

espaço parotídeo, bilateralmente, que contém a glândula parótida, o nervo facial e seus ramos e os linfonodos profundos da região; d) o espaço parafaríngeo, bilateralmente, subdividido em porções pré-estilóidea e pós-estilóidea, separadas pelo músculo tensor do véu palatino no nível da nasofaringe e pelo constritor da faringe no nível da or ofaringe.

2) O úni co ECP localizado excl usi vamente abaixo do osso hióide é o espaço visceral anterior ou compartimento visceral do pescoço, formado pelas três camadas da FCP (fig. 1), onde estão contidas a glândula tirói de, a laringe, a faringe, a traquéia e o esôfago cervical.

3) Entre os espaços situados ao longo de todo o pescoço, de acordo com os esquemas das figs. 1 e 2 , distinguem-se: a) o espaço retrofaríngeo, localizado entre a divisão visceral da CMFCP (posterior à faringe e ao esôfago) e a fáscia alar da CPFCP. Esse espaço tem seu limite cranial no nível da base do crânio e seu limite caudal no nível da 1a ou 2a vértebra torácica; b) o chamado "danger space", imediatamente posterior ao espaço retrofaríngeo, localizado entre a fáscia alar da CPFCP e a fáscia pré-vertebral da CPFCP, estendendo-se da base do crânio ao nível do diafragma; c) o espaço pré-vertebral, imediatamente posterior ao "danger space", localizado entre a fáscia pré-vertebral da CPF CP e a coluna cervical, estendendo-se da base do crânio ao cóccix; d) o espaço vascular ou espaço visceral vascular ou espaço visceral lateral, que contém o feixe vásculo-nervoso principal do pescoço (artérias carótidas comum, interna e externa, veia jugular interna e nervo vago) e é formado por contribuição das três camadas da FCP. 


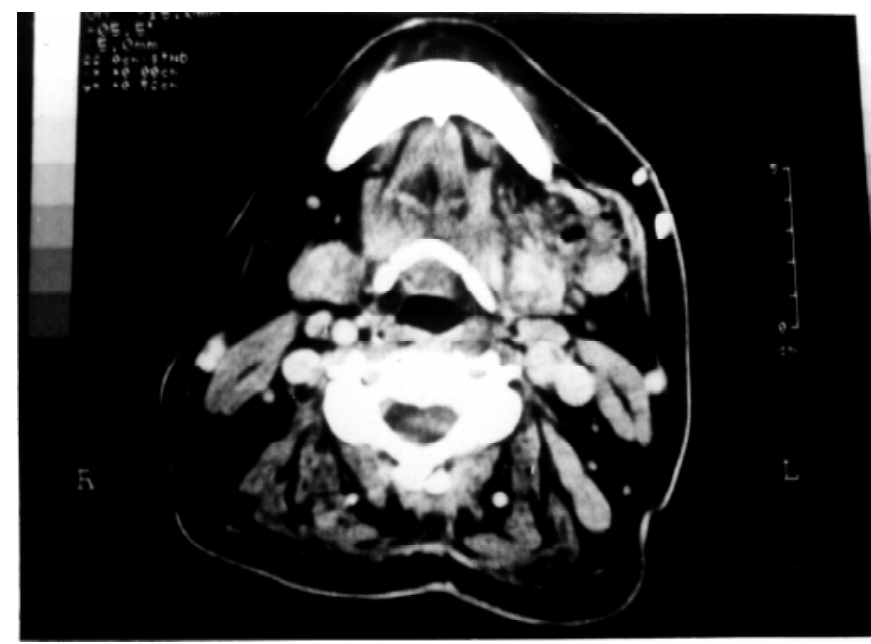

Fig. 3 - Tomografia computadorizada da transição cérvi co-facial do caso 1 evi denciando aumento de partes moles à esquerda e formação de gás.

\section{APRE SE NTAÇÃO DOS CASOS}

Caso 1 - Mulher de cor branca, 34 anos de idade, com queixa de abaulamento e dor em região submandibular esquerda há 6 meses. Foi tratada com antibióticos e antiinflamatórios não-hormonais nos períodos mais sintomáticos; teve episódios de melhora e piora. Tem história de múltiplo traumatismo há 5 anos, com penetração de fragmentos de vidro na face. Ao exame físico da admissão, estava em bom estado geral e tinha um abauIamento com sinais flogísticos na região submandibular esquerda. A ultra-sonografia revelava abscesso na loja submandibular esquerda, acometendo até mesmo a glândula submandibular. A tomografia computadorizada evidenciava processo inflamatório na região submandibular esquerda com aumento de partes moles e formação de gás (fig. 3). Na abordagem cirúrgica adotada para esgotar a loja submandibular esquerda, não foi encontrado corpo estranho. O exame anatomopatológico revelou sialadenite crônica supurativa submandibular. Na cultura do material, cresceu Escherichia coli. A evolução após o tratamento cirúrgico foi muito boa.

Caso 2 - Homem de cor branca, 31 anos de idade, que se queixava de abaulamento em região cervical lateral esquerda há uma semana, febre e intensa dor local. Era portador de diabetes melito insulinodependente (tipo 1) e, ao exame físico, apresentava regular estado geral, embora febril, sendo observado tumor inflamatório ocupando toda a extensão da região lateral esquerda do pescoço. Os exames laboratoriais indicavam descompensação do diabetes, hemograma com 21.000

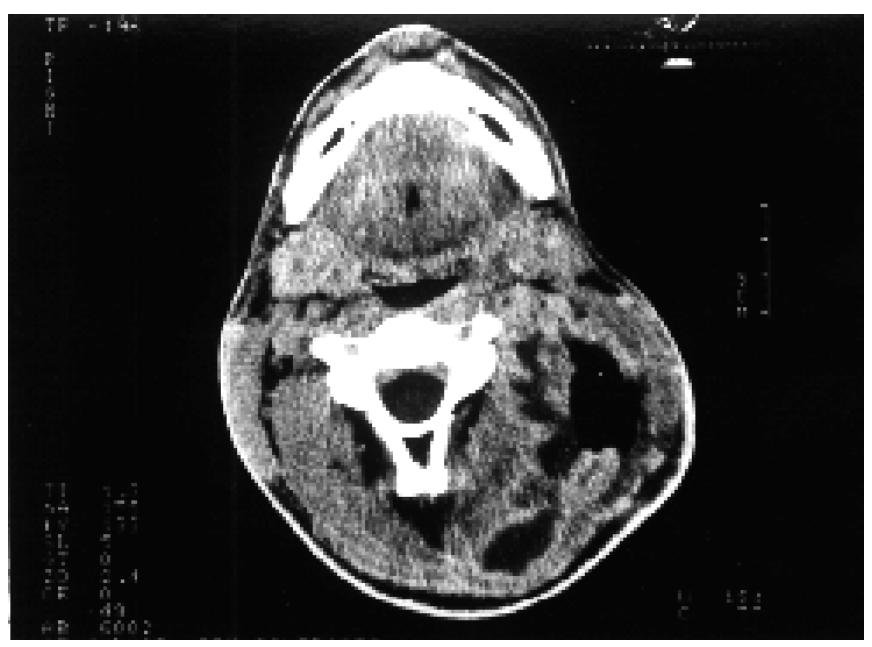

Fig. 4 - Tomografia computadorizada cervical do caso 2 evidenciando abscesso cervical à esquerda com formação de gás.

leucócitos e pesquisa de anticorpos anti-HIV negativa. A tomografia computadorizada revelava abscesso na região cervical lateral esquerda com formação de gás e dissecção de vários planos do pescoço (fig. 4). O feixe vásculo-nervoso estava localizado medial mente ao abscesso. I nicialmente, o doente foi tratado com penicilina cristalina e amicacina. Como não obtivesse mel hora, 24 horas após o início da antibioticoterapia, foi submetido à drenagem do abscesso, feita por cervi cotomia lateral esquerda junto à borda posterior do músculo esternoclidomastóideo. A penicilina cristalina foi substituída por clindamicina. Pelo dreno de Penrose, colocado no local do abscesso, saiu pequena quantidade de pus por, aproximadamente, uma semana. O doente evoluiu com melhora do estado geral e compensação do diabetes melito no pósoperatório. Na cultura do material drenado, houve crescimento de Staphylococcus aureus.

Caso 3 - J ovem do sexo feminino, branca, de 19 anos, que apresentava abaulamento e dor em região submandibular direita há onze dias. O quadro progrediu rapidamente, com febre alta e disfagia, apesar do uso de fenoximetilpenicilina por via oral. Relatava a extração do segundo molar inferior direito onze dias antes da consulta. O exame físico revelava abaulamento cervical, acompanhado de edema e sinais flogísticos, que se estendia desde a região submandibular di reita até a fúrcula esternal, além de intenso comprometimento do estado geral. A pesquisa de anti corpos anti-HIV foi negativa e a dosagem de imunogl obulinas, normal . Apesar da antibioticoterapia com cefalotina e metronidazol, não houve mel hora em 24 horas. No segundo dia de internação, surgiu tosse seca, dor 


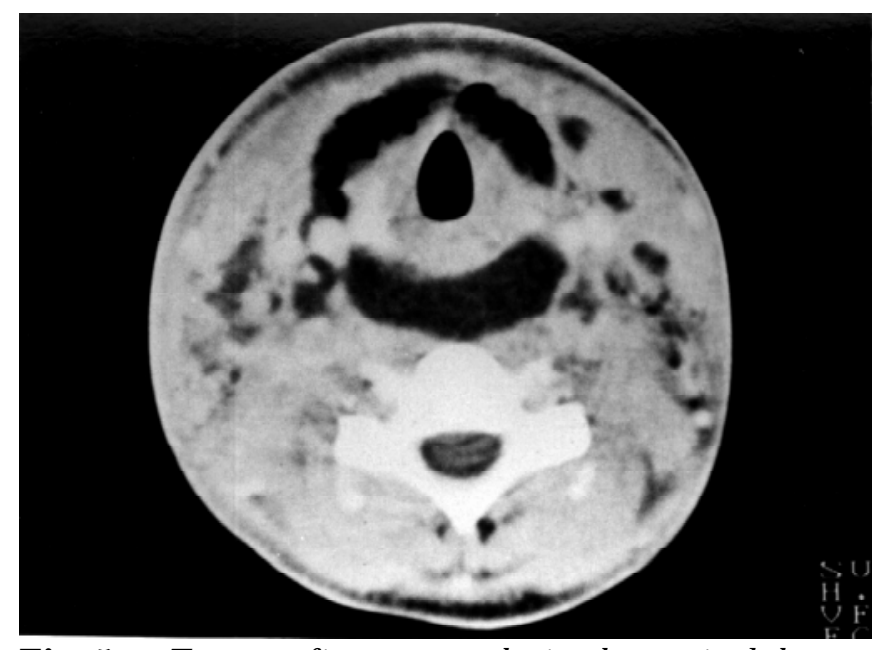

Fig. 5 - Tomografia computadorizada cervical do caso 3. Observar o contorno arredondado do pescoço e a dissecção do danger space pelo abscesso.

retroesternal, aumento do edema cervical e afagia. $O$ raio $X$ do pescoço mostrava aumento do espaço retrofaríngeo e enfisema de partes moles cervicais. A tomografia computadorizada de pescoço e tórax mostrava coleção retrofaríngea extensa em todos os espaços cérvico-fasciais em continuidade com o espaço retroesternal, estendendo-se ao mediastino posterior e à cúpula diafragmática (figs. 5 e 6). A tomografia computadorizada evidenciava, ainda, derrame pleural bilateral e broncopneumonia de base direita. A doente foi submetida a cervicotomia exploradora e drenagem das col eções cervicais, de onde saíram $700 \mathrm{~mL}$ de pus, drenagem do mediastino superior, anterior e posterior. Foram introduzidas amicacina, clindamicina e ceftriaxona. A doente evoluiu com choque séptico no pós-operatório imediato e, no dia seguinte, apresentava sinais ecocardiográficos de derrame pericárdico, sendo submetida a toracotomia ântero-lateral direita, drenagem mediastinal anterior e posterior do derrame pericárdico purulento, drenagem do hemitórax direito anterior e posterior, e drenagem fechada do hemitórax esquerdo. Na cultura do material obti do na primei ra e segunda intervenções cirúrgicas cresceu Staphylococcus aureus. Após a operação, a doente evoluiu com pneumonia em todo o campo direito e na base esquerda, e abscessos metastáticos subcutâneos no pescoço. U ma fístula esofágica de $0,4 \mathrm{~cm}$ delargura foi demonstrada pela endoscopia, estendendo-se por cerca de $1 \mathrm{~cm}$ para o espaço cervical vizinho e iniciando-se na parede lateral direita do esôfago, 4cm abaixo do esfíncter esofágico superior. Em função do resultado da cultura, foi mudado o esquema antibiótico para ceftazidima e vancomicina. A tomografia computadorizada de controle

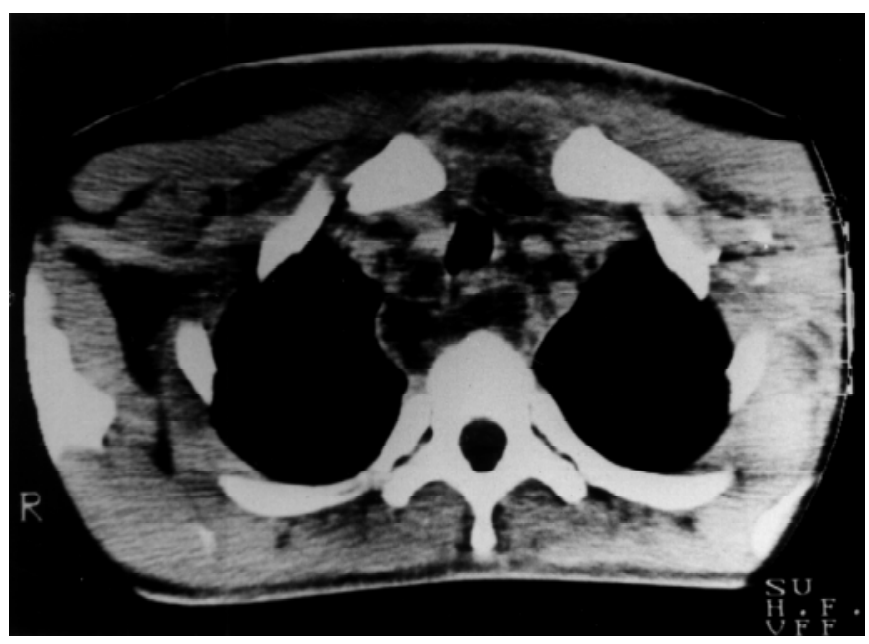

Fig. 6 - Tomografia computadorizada de tórax do caso 3. Notar a disseminação do abscesso para o mediastino posterior por meio do danger space.

evidenciava o aumento da loja mediastinal pela fístula esofágica, de tal maneira que a paciente teve que ser submetida a nova operação para redrenagem das lojas mediastinais e redirecionamento da fístula esofági ca para a região posterior do hemitórax direito. A partir do sétimo dia de internação, a paciente começou a evoluir com meIhora, apesar de ter sido observada na endoscopia digestiva alta a ampliação da fístula esofágica $(2,5 \mathrm{~cm} \times 0,4 \mathrm{~cm})$ para o hemitórax direito, que já havia sido drenado. A paciente recebeu alta no $54^{\circ}$ dia de internação, com fístula esôfago-mediastinal e drenagem aberta tóraco-mediastinal. Após 45 dias da alta hospitalar, a fístula fechou-se. A doente havia perdido, desde o início do quadro infeccioso, $25 \%$ do seu peso habitual.

Caso 4 - Mulher branca, de 33 anos, com 20 dias de abaulamento e dor nas regiões massetérica e submandibular esquerdas, assim como nas proximidades do ângulo da mandíbula. Referia manipulação dentária do $2^{\circ}$ pré-molar inferior esquerdo 30 dias antes. A doente já havia sidotratada durante os 20 dias que antecederam a consulta com anti inflamatóri os não-hormonais exclusivamente. Há um dia, apresentava febre e piora da dor. O examefísico revelava regular estado geral ediscreto desconforto respiratório. O exame do pescoço mostrava abaulamento e sinais flogísticos, em toda sua região lateral esquerda, e desvio da traquéia para a direita. A oroscopia revelava abaulamento de região amigdaliana, parede lateral da or ofaringe e palato mole. A pesquisa de anticorpos anti-HIV foi negativa. A tomografia computadorizada de face e pescoço revel ou extenso abscesso na região parafaríngea esquerda. À internação, foi iniciada penicilina cristalina e amicacina. Como 


\begin{tabular}{|c|c|c|c|c|}
\hline \multicolumn{5}{|c|}{ Quadro - Resumo dos dados clínicos } \\
\hline Dados & Caso 1 & Caso 2 & Caso 3 & Caso 4 \\
\hline Idade & $34 a$ & $31 a$ & $19 a$ & $33 a$ \\
\hline Sexo & fem. & masc. & fem. & fem. \\
\hline Queixa e duração & 24 semanas & 1 semana & 11 dias & 3 semanas \\
\hline História & $\begin{array}{l}\text { 5a. traumat + corpo } \\
\text { estranho }\end{array}$ & diabetes melito & extração dentária & manipulação dentária \\
\hline Tratamento prévio & $\begin{array}{l}\text { antibiótico, } \\
\text { antiinflamatórios }\end{array}$ & analgésico & antibiótico & antibiótico por 20 dias \\
\hline Sintomas & $\begin{array}{l}\text { dor, tumor } \\
\text { submandibular }\end{array}$ & $\begin{array}{l}\text { dor, tumor cervical } \\
\text { lateral, febre alta }\end{array}$ & $\begin{array}{l}\text { dor, tumor lateral } \\
\text { extenso, febre alta, } \\
\text { disfagia, angina Ludwig }\end{array}$ & $\begin{array}{l}\text { dor, febre e tumor mas- } \\
\text { seterino e submandibular }\end{array}$ \\
\hline Exame geral & $\begin{array}{l}\text { bom estado geral, } \\
\text { subfebril }\end{array}$ & $\begin{array}{l}\text { regular estado geral, } \\
\text { febre }\end{array}$ & mau estado geral, febre & $\begin{array}{l}\text { regular estado geral, } \\
\text { febre }\end{array}$ \\
\hline $\mathrm{RX}$ & - & - & $\begin{array}{l}\text { aumento de espaço } \\
\text { retrofaríngeo }\end{array}$ & - \\
\hline Ultra-som & $\begin{array}{l}\text { abscesso submandibular } \\
\text { c/ gás }\end{array}$ & - & - & - \\
\hline Tomografia & abscesso cervical c/ gás & abscesso cervical c/ gás & $\begin{array}{l}\text { extensa coleção retro- } \\
\text { faríngea retroesternal, } \\
\text { mediastínica, derrame } \\
\text { pleural, roncopneumonia }\end{array}$ & $\begin{array}{l}\text { extenso abscesso } \\
\text { parafaríngeo }\end{array}$ \\
\hline Espaços cervicais & submandibular & $\begin{array}{l}\text { parafaríngeo pré-estilóide } \\
\text { e retrofaríngeo }\end{array}$ & $\begin{array}{l}\text { todos os espaços } \\
\text { cervicais, mediastínico } \\
\text { e pleural }\end{array}$ & $\begin{array}{l}\text { submandibular, sublin- } \\
\text { gual, parafaríngeo, } \\
\text { pré-estilóide }\end{array}$ \\
\hline Tratamento & $\begin{array}{l}\text { drenagem + antibióticos } \\
\text { sem traqueostomia }\end{array}$ & antibióticos + drenagem & $\begin{array}{l}\text { antibióticos + drenagem } \\
+ \text { toracotomia }+ \\
\text { traqueostomia }\end{array}$ & $\begin{array}{l}\text { antibióticos + drenagem } \\
\text { transoral }\end{array}$ \\
\hline Exame anatomopatológico & sialadenite supurativa & - & - & - \\
\hline Cultura & Escherichia coli & Staphylococcus aureus & Staphylococcus aureus & * \\
\hline Evolução & cura em uma semana & cura em uma semana & cura em 18 semanas & cura em duas semanas \\
\hline
\end{tabular}

não houvesse mel hora após 24 horas do tratamento, foi indicado procedimento cirúrgico, que consistiu na drenagem, por via transoral, de aproximadamente $50 \mathrm{~mL}$ de pus do abscesso, por meio de sonda de Foley com duas vias, para manter a lavagem da loja. O esquema antibiótico foi modificado com a introdução de clindamicina e amicacina. A paciente evoluiu bem no pós-operatório, com resolução completa do quadro.

O quadro acima apresenta uma sinopse dos casos supra-apresentados.

\section{DISCUSSÃO}

As IECP passaram a ser quadros mais infreqüentes desde a introdução dos antibióticos na prática clínica, na década de 1940. Nos últimos vinte anos, porém, sua freqüência aumentou devido ao abuso de drogas por via intravenosa ${ }^{2,4,5}$. A causa mais comum das IECP são, em crianças, as amigdalites agudas que podem levar aos abscessos peritonsilares, e, em adultos, os focos dentários que, seja por infecção ou manipulação, provocam abscessos da região submandibular ${ }^{1,2,6}$.

As IECP comprometem os espaços determinados pelas camadas da fáscia cervical profunda (FCP) e pel as suas subdi visões, como vimos anteri ormente. São consideradas verdadeiras fasciítes, embora tal termo seja mais usado com referência às infecções envol vendo a fáscia cervical superficial. A condensação das camadas e subdivisões da FCP definem os espaços profundos do pescoço, que, uma vez infectados, tendem a conter o processo infeccioso, evitando sua dissemi nação, até certo ponto em que a pressão exercida pelo abscesso vence a resistência da fáscia e provoca a disseminação da doença para outro espaço.

U ma das grandes dificuldades enfrentadas nas IECP é fazer o diagnóstico precoce. Na maioria das vezes, ele só é feito em fase mais tardia da doença, quando sintomas e sinais são mais evidentes e o estado geral do paciente já está comprometido ${ }^{2,4,7}$. 
Por essa razão, muitos doentes acabam sendo tratados pel a cirurgia associada à antibioticoterapia. Se o diagnóstico for feito em fases mais precoces da infecção, pode ser empregada apenas a antibioticoterapia de amplo espectro. Outros fatores que podem indicar a modalidade terapêutica a adotar são a origem da infecção e o espaço comprometi do. Exemplificando, os portadores de abscesso retrofaríngeo são tratados, na maioria das vezes, com antibioticoterapia exclusiva. Diferentemente, para os portadores de angina de Ludwig, salvo raras exceções, é utilizada terapêutica combinada (antibioticoterapia mais abordagem cirúrgica).

A angina de Ludwig é um quadro clássico, descrito em 1836 por Wilhel $m$ von Ludwig, e consiste na infecção do espaço submandibular. De acordo com Grodinsky \& Holyoke ${ }^{8}$, acomete os dois componentes do espaço submandibular (espaço sublingual e espaço submaxilar). Para se firmar o diagnóstico de angina de Ludwig, as seguintes características devem ser observadas: a) o processo iniciase no soal ho da boca, usual mente com a infecção de 2o ou 3o molar inferior; b) a disseminação ocorre para o espaço submandi bular mais por contigüidade, pelos planos das fáscias, do que pelos vasos linfáticos; c) a infecção apresenta-se como um endurecimento da região submandibular, sem formação de muito pus; d) o processo poupa as glândulas salivares elinfonodos; e) a infecção é, usualmente, bilateral. Na angina de Ludwig, o edema leva ao deslocamento da língua em di reção posterior e superior, acarretando obstrução respiratória. O tratamento é combinado, na maioria dos casos, devendo-se introduzir, precocemente, antibioticoterapia contra germes gram-positivos aeróbios e anaeróbios. A abordagem cirúrgica consiste na drenagem da loja submandibular e na traqueostomia, quando necessária, o que pode chegar a $50 \%$ dos casos. O material drenado é utilizado para estudo bacteriológico, com o objetivo de reorientar a antibioticoterapia no pós-operatório.

Mais recentemente, um grande número de IECP tem sido descrito como resultado da utilização de drogas endovenosas injetadas nas grandes veias do pescoço (veia jugular externa e veia jugular interna $)^{2,4}$. Ao injetar tais drogas nos vasos principais do pescoço, os usuários violam a proteção dada pelas fáscias cervicais e, com agulhas infectadas, contaminam os espaços cervicais profundos, favorecendo as infecções profundas. Clinicamente, o doente refere história de uso recente de drogas endovenosas no pescoço e apresenta-se com abaulamento doloroso cervical. O quadro clínico pode evoluir com febre, disfagia, rouquidão e dispnéia. O diagnóstico pode ser complementado pel os exames de imagem, que revelam, de hábito, o comprometimento de vários espaços cervicais profundos. $\mathrm{Na}$ abordagem desses doentes, é imperativo garantir a permeabilidade das vias aéreas, que poderá estar prejudicada por edema delaringe ou compressão extrínseca da laringe ou da traquéia. Observado o quadro clínico, o doente deverá ser internado e submetido a um esquema antibioticoterápico adequado. U ma vez que tais infecções têm como principal agente etiológico o Staphylococcus aureus, os antibióticos de escol ha são penicilina, clindamicina, oxacilina e cefalosporinas de primeira geração. Após 24 a 48 horas de antibioti coterapia, não sendo observada melhora do quadro clínico, a drenagem cirúrgi ca estará indicada. A antibioticoterapia deverá ser corrigida de acordo com o resultado do estudo bacteriológico do material drenado. Além das IECP, há outros resultados prejudiciais da injeção de drogas feita nos grandes vasos do pescoço ${ }^{4}$. Entre as mais comuns estão a paralisia de corda vocal e a síndrome de Horner, ambas devidas a lesão de estruturas nervosas cervicais. A injeção acidental na artéria carótida pode levar a seqüelas neurológicas graves, tanto em função dos efeitos da droga como do desenvolvimento de oclusão arterial, fenômenos tromboembólicos ou aneurismas mi cóticos da caróti da. Outras complicações, descritas na literatura, são: pancreatite, pneumonia, quadriplegia, osteomielite, tromboembolismo pulmonar, meningite e abscesso cerebral.

O abscesso peritonsilar é a forma mais comum de abscesso do segmento aerodigestivo alto ${ }^{6,9}$. Associado, quase na totalidade dos casos, com a amigdalite aguda, o processo infeccioso progride surgindo coleção purulenta entre a cápsula da amígdala e a fáscia do músculo constritor superior da faringe. Os indivíduos mais atingidos são os da $1^{\text {a }}$ e 2a décadas da vida. N ormalmente, esse abscesso situa-se junto ao pólo superior da amígdala, mas várias localizações já foram descritas. O portador desse tipo de afecção, geralmente, tem sepse, odinofagia, disfagia e trismo. No exame físico, pode haver eritema, edema da Ioja amigdaliana e deslocamento da amígdala em direção da linha média. A úvula encontra-se desviada no sentido contrário ao do lado comprometido. O espaço parafaríngeo deve estar livre, o que é evidenciável pela tomografia computadorizada. A melhor conduta é a drenagem ${ }^{2,6,9}$. A necessidade de praticar a ami dal ectomia relaciona-se com a presença de abscessos peritonsilares recorrentes ou a história de amigdalite crônica, não sendo indicada, no entanto, em um episódio isolado de abscesso peritonsilar ${ }^{5}$. Atualmente, alguns autores preconizam a 
aspiração do material purulento com agulha, em seguida higiene oral, antibioticoterapia e dieta leve. A maioria dos casos tende à resolução por esse método, apelando-se para a drenagem, em caso de insucesso ${ }^{6}$.

Os abscessos do espaço parafaríngeo são resultantes da disseminação de um foco de infecção do trato aerodigestivo, como amigdalites, faringites, sinusites ou infecções odontogênicas ${ }^{2,7}$. No entanto, em aproximadamente $50 \%$ dos casos não se encontra um sítio primário de origem definida. $\mathrm{O}$ portador de abscesso no espaço parafaríngeo, com freqüência, exibe trismo e limitação dos movimentos cervicais. Algumas vezes ocorre meningismo, em função da irritação dos músculos paraespinhais. Além desses sinais, pode ser encontrado, no exame físico, desvio da parede lateral da faringe e da amígdala em direção à linha média e endureci mento dos teci dos mol es cervicais. Flutuação raramente é observada. Esses doentes devem ser internados e submetidos a altas doses de antibioticoterapia empírica contra Streptococcus, Staphylococcus e anaeróbios da cavidade oral, que são os principais causadores do quadro infeccioso. $O$ esquema antibioticoterápi co será mantido ou substituído de acordo com a bacterioscopia e a cultura do material purulento obtido por meio de aspiração por agulha. Havendo abscesso, ele poderá ser drenado, mediante cervicotomia submandibular atingindo o espaço parafaríngeo anterior em posição medial ao ventre posterior do músculo digástrico. A drenagem transoral pode ser perigosa por causa da dificuldade em identificar e preservar importantes estruturas vásculo-nervosas adjacentes ao espaço parafaríngeo.

As infecções do espaço retrofaríngeo podem ter origem no comprometimento dos linfonodos que repousam nesse espaço por parte de bactérias que infectam primariamente nariz, faringe e seios paranasais (disseminação linfática). Tem sido lembrado que, com o passar dos anos, há a tendência à atrofia desses linfonodos, fato que explicaria a maior incidência dessas infecções nas crianças $^{2,6,9}$. Outra causa é o ferimento penetrante da parede posterior da faringe, que pode ocorrer, iatrogenicamente, em endoscopia ou intubação orotraqueal ${ }^{6}$. O espaço retrofaríngeo possui uma rafe mediana que tende a conter o abscesso de um só lado, o que explica alguns dos sinais clínicos a seguir mencionados. O portador dessa afecção apresenta, geralmente, dor, febre e leucocitose. Odinofagia e disfagi a são freqüentes, assi m como o deslocamento anterior da parede posterior da faringe. Pode haver assimetria da faringe. A inflamação dos músculos paraespinhais pode provocar o opistótono. Portadores de infecção do espaço retrofaríngeo devem ser internados e submetidos a altas doses de antibióticos endovenosos. Nos abscessos, deve ser drenado o espaço retrofaríngeo. Se o abscesso está localizado apenas nesse espaço, sem evidência de disseminação para outros espaços, a abordagem pode ser transoral, com os devidos cuidados para evitar a aspiração do pus para as vias aéreas. Desta forma, o procedimento é feito sob anestesia geral e com intubação orotraqueal por meio de cânula endotraqueal dotada de cuff, usando-se sempre o aparel ho de sucção. A infecção do espaço retrofaríngeo pode progredir para envolvimento do mediastino por mei o do danger space e do espaço pré-vertebral, provocando complicações por vezes fatais. Rápida e efetiva abordagem terapêutica se faz necessária nesses doentes.

As infecções do espaço pré-vertebral, quase sempre, começam por uma osteomielite do corpo vertebral $^{6}$. O exemplo clássico é a osteomielite vertebral tuberculosa (ou doença de Pott), que se dissemina para o espaço pré-vertebral. Esse espaço virtual estende-se até o cóccix, consistindo via direta de disseminação para o tórax e mediastino ou para o espaço retroperitonial. O tratamento das infecções do espaço pré-vertebral requer drenagem, antibioticoterapia em altas doses e, em alguns casos, estabilização da posição da coluna. 0 espaço pré-vertebral pode, ainda, ser acometido por infecções oriundas de outros espaços cervicais profundos, possibilitando a sua disseminação para o mediastino e tórax².

Outras causas de IE CP são as infecções de glândulas salivares, traumatismo e introdução de corpo estranho, mas, em aproximadamente $20 \%$ dos casos, não se consegue estabelecer a causa.

Os exames imagenológi cos são de capital importância para avaliar IE CP. O RX simples da região cervical pode mostrar, além do aumento de volume das partes moles, desvio da traquéia, presença de corpo estranho (agulha, por exemplo), perda da Iordose cervical normalmante observada e osteomielite de corpo vertebral. O RX é útil, também, para distinguir entre infecções superficiais e profundas. A tomografia computadorizada, juntamente com a ressonância nuclear magnética, pode nos dar, com precisão, as dimensões e a local ização de um abscesso cervical. Freqüentemente, mais de um espaço está comprometido pela IECP, o que é evidenciável por meio da tomografia computadorizada e ressonância nuclear magnética. Outros aspectos à tomografia das IECP são o aumento de partes moles e a perda do contorno ovalado do pescoço nos cortes axiais, que passa a ser arredondado. A tomografia computadorizada possibilita 
ao cirurgião planejar mel hor a abordagem no caso de precisar drenar esses casos e avaliar a evolução da terapêutica instituída.

\section{CONCLUSÕES}

As IECP têm etiologia diversificada (infecções dentárias, uso de drogas endovenosas, infecções do trato aerodigestivo alto e outras) e são quadros associados a altas mor bi dade e mortalidade. A abordagem cirúrgica se impõe pela necessidade de traqueostomia em cerca de $50 \%$ dos casos. Como regra geral, a terapêutica é, inicialmente, clínica, com introdução de anti bi oticoterapia de amplo espectro. Quando não se observa mel hora nas primeiras 24 ou 48 horas, indica-se a cirurgia para drenagem do espaço comprometido. Para isso, o cirurgião deve estar atento às particularidades da anatomia das fáscias e dos espaços cervicais. Os métodos imagenológi cos são imprescindíveis para a aval iação de infecções dos espaços profundos do pescoço, tanto na avaliação do sítio e extensão da afecção como no planejamento e no controle terapêutico.

\section{SUMMARY}

\section{Deep neck spaces and their interest in cervical infections}

BACKGROUND. Although rare, deep neck space infections are associated with high morbidity and mortality rates. The surgical approach is necessary in the majority of the cases, and the surgeon must know the complex anatomy of the cervical fasciaeand deep neck spaces.

Purpose. The anatomy of the cervical fasciae and deep neck spaces is reviewed. As an illustration, a series of deep neck space infections is presented.

Material and Method. Four clinical cases are reported: 1) a case of Ludwig's angina with several complications (mediastinitis, pericarditis, pneumonia, pleural effusion and empyema, esophageal fistula and septic shock), 2) a case of cervical abscess that appeared without apparent cause, in a young diabetic patient, 3) a case of abscess of the submandibular triangle, and 4) a case of parapharyngeal abscess that came forth after a dental treatment. Data from history taking, physical examination, Xrays, echography, CT scan and treatment and the follow-up are presented. The image tests were valuableand, in two of the cases, they demonstrated that more than one deep neck space were affected.

Conclusions. The literature reinforces the high mortality and morbidity rates, the diversified etiology (dental infection, intravenous drug abuse, infections of the upper aerodigestive tract and others), and the tracheostomy indication made in about half of the cases. It stresses al so the need for combined therapy (antibiotics and surgery). Evaluation with CT scan and other radiologic methods is indispensable to determine the site and extent of the process and to plan properly the treatment [Rev Ass Med Brasil 1997; 43(2): 119-26.]

KEY WoRdS: Cervical infections. Deep neck space infections. Cervical abscesses. Anatomy of cervical fasciae. Ludwig's angina.

\section{REFERÊNCIAS BIBLIOGRÁFICAS}

1. Hollinshead WH. Anatomy for surgeons - thehead and neck, $3^{\text {rd }}$ ed. Philadel phia, J .B. L ppincott, 1982; 269-89.

2. Scott BA, Stiernberg CM. Deep neck space infections. In Bailey BJ (ed): Head \& Neck Surgery-Otolaryngology, $1^{\text {st. }}$ ed. Philadel phia, J .B. Lippincott, 1993; 738-53.

3. Bielamowicz SA, Storper IS, J abour BA, Lufkin RB, Hanafee WN. Spaces and triangles of the head and neck. Head \& Neck 1994; 16: 383-8.

4. Myers EM, Kirkland J r LS, Mickey, R. The head and neck sequelae of cervical intravenous drug abuse. Laryngoscope 1988; 98: 213-8.

5. Tom MB, Rice DH. Presentation and management of neck abscess: a retrospective analysis. Laryngoscope 1988; 98: 87781

6. J ohnson J T. Abscesses and deep space infections of the head and neck. Infect Dis Clin North Am 1992; 6: 705-17.

7. Patterson HC, Kelly J H, Stome M. Ludwig's angina: an update. Laryngoscope 1982; 92: 370-7.

8. Grodinsky M, Holyoke EA. The fasciae and fascial spaces of the head, neck and adjacent region. AmJ Anat 1938; 63: 367.

9. Dodds B, Maniglia AJ . Peritonsillar and neck abscesses in the pediatric age group. Laryngoscope 1988; 98: 956-8. 